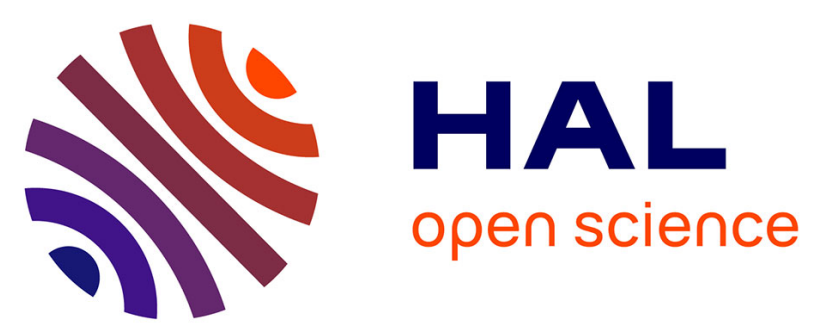

\title{
Black Silicon Photoanodes Entirely Prepared with Abundant Materials by Low-Cost Wet Methods
}

\author{
K. Oh, L. Joanny, F. Gouttefangeas, Bruno Fabre, V. Dorcet, B. \\ Lassalle-Kaiser, A. Vacher, Cristelle Mériadec, S. Ababou-Girard, Gabriel \\ Loget
}

\section{To cite this version:}

K. Oh, L. Joanny, F. Gouttefangeas, Bruno Fabre, V. Dorcet, et al.. Black Silicon Photoanodes Entirely Prepared with Abundant Materials by Low-Cost Wet Methods. ACS Applied Energy Materials, 2019, ACS Appl. Energy Mater., 2 (2), pp.1006. 10.1021/acsaem.8b02229 . hal-02086216

\section{HAL Id: hal-02086216 \\ https://hal-univ-rennes1.archives-ouvertes.fr/hal-02086216}

Submitted on 15 Apr 2019

HAL is a multi-disciplinary open access archive for the deposit and dissemination of scientific research documents, whether they are published or not. The documents may come from teaching and research institutions in France or abroad, or from public or private research centers.
L'archive ouverte pluridisciplinaire HAL, est destinée au dépôt et à la diffusion de documents scientifiques de niveau recherche, publiés ou non, émanant des établissements d'enseignement et de recherche français ou étrangers, des laboratoires publics ou privés. 


\title{
Black Silicon Photoanodes Entirely Prepared with
}

\section{Abundant Materials by Low-Cost Wet Methods}

\author{
K. Oh, ${ }^{1}$ L. Joanny, ${ }^{2}$ F. Gouttefangeas, ${ }^{2}$ B. Fabre, ${ }^{1}$ V. Dorcet,,${ }^{1,2}$ B. Lassalle-Kaiser, ${ }^{4}$ A. Vacher, ${ }^{1}$ \\ C. Mériadec, ${ }^{3}$ S. Ababou-Girard, ${ }^{3}$ G. Loget $^{1 *}$ \\ *gabriel.loget@univ-rennes1.fr
}

1. Univ Rennes, CNRS, ISCR (Institut des Sciences Chimiques de Rennes)-UMR6226, F-35000

Rennes, France.

2. Univ Rennes, CNRS, ScanMAT-UMS2001, F-35000 Rennes, France.

3. Univ Rennes, CNRS, IPR (Institut de Physique de Rennes)-UMR6251, F-35000 Rennes, France.

4. Synchrotron SOLEIL, L'Orme des Merisiers, Saint-Aubin, 91192 Gif-sur-Yvette, France.

KEYWORDS. solar energy conversion, oxygen evolution reaction, nickel, silicon, iron 


\begin{abstract}
We report a new design for water-splitting photoanodes, based on a highly absorbing black silicon (BSi) substrate modified with catalytic metal nanoparticles (NPs). The overall fabrication strategy is cost-efficient as it only requires the use of abundant materials and simple wet procedures such as electrochemical etching and electrodeposition and does not involve the use of buried homojunction and protection layer. Importantly, these results demonstrate that electrodeposited transition metal NPs can stabilize structured Si photoelectrodes without the need for a protection layer.
\end{abstract}

The depletion of fossil fuels and the increasing environmental pollution imply an urgent development of alternative technologies to foster the energy transition. ${ }^{1}$ In this frame, the largescale use of solar energy is particularly promising because this is the most abundant renewable energy on Earth. ${ }^{2}$ Solar energy research went through a frantic period after the oil crisis in the early seventies and, in this period, water-splitting photoelectrochemical cells (PECs) started to gain attention. ${ }^{3}$ These devices are based on light-absorbing semiconductor (SC) materials interfaced with a liquid phase. Under illumination, the charge carriers generated in the SC phase are driven to the solid-liquid interface where they react to generate products in solution. ${ }^{4}$ In the case of water-splitting PECs, photogenerated holes $\left(h^{+}\right)$and electrons $\left(e^{-}\right)$respectively oxidize and reduce water to generate $\mathrm{O}_{2}$ and $\mathrm{H}_{2}$, the latter being a highly promising clean energy carrier. ${ }^{1}$ An effective utilization of sunlight is required for PEC systems, which can be ideally done by employing small band gap and/or structured SCs. ${ }^{5} \mathrm{Si}$ is a highly abundant low band gap SC $\left(E_{g}=\right.$ $1.1 \mathrm{eV}$ ) that would be an excellent candidate for manufacturing PECs, especially because this material can be readily processed at the industrial level. ${ }^{6}$ However, Si is difficult to be employed as a photoelectrode due to its notorious instability. This issue is even more pronounced when $\mathrm{Si}$ 
is used as a photoanode in alkaline media because of: $i$ ) photocorrosion which induces fast electrochemical deactivation by generating an insulating $\mathrm{SiO}_{\mathrm{x}}$ layer $^{7}$ and $i i$ ) alkaline etching (AE) which causes the irreversible dissolution of the material. ${ }^{8}$ The main strategy reported so far for manufacturing stable Si-based oxygen evolution reaction (OER) photoanodes consisted in first modifying the Si surface with a transparent and conformal protection layer such as $\mathrm{TiO}_{2},{ }^{9}, 10$ $\mathrm{Al}_{2} \mathrm{O}_{3},{ }^{11} \mathrm{SiO}_{2}{ }^{12}$ and then applying a co-catalytic (cocat) coating in order to improve oxygen evolution reaction OER kinetics. Recently, unexpected reports from our group ${ }^{13,14}$ and others ${ }^{15,16,17}$ have revealed that heterogeneous nanoscale pinched-off $n$-Si/metal (metal $=\mathrm{Ni}$ or Co) junctions, prepared only by a simple aqueous-phase electrodeposition process, can be employed to manufacture Si photoanodes exhibiting high photocurrent densities and stability without a protection layer. In addition, we have shown lately that these photoanodes can be implemented in complete monolithic water-splitting PEC to produce $\mathrm{H}_{2}$ under simulated sunlight. ${ }^{18}$ The transposition of this concept to structured $n$-Si surfaces has been reported only once, ${ }^{19}$ however, with a Si structuration process based on lithography and vacuum-based physical methods. ${ }^{19}$ In addition, there has been recently a strong interest in producing photoelectrode based on black silicon (BSi) (that is, highly absorbing structured $\mathrm{Si}$ ). ${ }^{20,21}$ These systems required, so far, the use of a $\mathrm{TiO}_{2}$ protection layer deposited by atomic layer deposition (ALD). ${ }^{22}$ In this communication, we report the first example of protection layer-free BSi photoanode, prepared by a simple and cost-efficient electrodeposition strategy.

The fabrication strategy is described in Scheme 1. First, $n$-type $\operatorname{Si}(100)$ wafers were structured by employing a rapid ( $<10 \mathrm{~min})$ two-step method previously introduced by our group to fabricate $\mathrm{a} \sim 10 \mu \mathrm{m}$-thick porous Si layer (Figure 1a) composed of vertically-aligned macropores bearing 
spikes at their extremities (Figure 1b). As previously reported, ${ }^{23}$ these structures efficiently trap the incident light, as shown by their pitch-black visual appearance and their low reflectance (vide infra), we refer herein to them as BSi. Next, we modified the BSi surfaces with a catalytic and stabilizing coating. Toward this goal, we first electroplated $\mathrm{Ni}^{0}$ on the freshly-hydrogenated $\mathrm{BSi}$ using the same method as the one previously employed on planar $\mathrm{Si}^{13,14}$ This electrodeposition leads to the homogeneous decoration of the porous BSi layer with randomly-dispersed $\mathrm{Ni}$ nanoparticles (NPs). The role of these NPs role is to generate an array of robust nanoscale Schottky junctions, promoting an efficient hole transfer across the $\mathrm{Si} / \mathrm{Ni}$ and $\mathrm{Ni} / \mathrm{electrolyte}$ interface as well as a high photovoltage for sunlight-assisted OER, caused by the pinch-off effect. ${ }^{24-26}$ In addition, considering that NiFe alloys are currently among the best OER electrocatalysts, ${ }^{27}$ and that Fe incorporation improves OER kinetics in Si/Ni planar photoanodes, ${ }^{14}$ we have decided to coat the Ni NPs with a NiFe layer by a second aqueous electrodeposition step. To do so, the BSi surfaces modified by the Ni NPs were first thermally oxidized after the first electrodeposition step by placing them into an oven at $90^{\circ} \mathrm{C}$ for $1 \mathrm{~h}$, in order to generate $\mathrm{SiO}_{\mathrm{x}}$ layer onto the unprotected $\mathrm{Si}$ surface (red color in Scheme 1). The presence of this electrically-passivating layer ensures the electrodeposition of the NiFe coating only on the Ni NPs by preventing the deposition on the BSi, as shown in Scheme 1 (note that the electrodeposition was performed employing an aqueous electrolyte containing $\mathrm{Ni}$ and Fe salts at a 10/1 molar ratio, see SI and Figure S4 for more details). Scanning and transmission electron microscopy (SEM and TEM) analyses were performed before and after electrodeposition in order to characterize the coatings. Cross-section SEM (Figure 1c), confirmed the presence of randomly-dispersed Ni/NiFe NPs on the walls of the BSi pores and spikes. In addition, TEM allowed a clear morphological characterization of the Si/Ni nanoscale Schottky junctions (Figure 
1d) as well as the metal NPs (inset of Figure 1d). As shown in these figures, the metal particles were hemispherical with diameters below $100 \mathrm{~nm}$.

The chemical composition of the modified surfaces was determined by employing several methods. First, scanning transmission electron microscopy coupled with energy-dispersive X-ray spectroscopy (STEM-EDS) mapping (Figure 2a-d), performed on a BSi area containing 2 isolated NPs (Figure 2a), confirmed the presence of Si in the substrate (red signal in Figure 2b) and $\mathrm{Ni}$ in the NPs (blue signal in Figure 2c). However, Fe mapping shown in Figure 2d was not fully conclusive: whereas its presence could be discerned for the largest NP, it was not possible to observe it for the smallest NP. X-ray photoelectron spectroscopy (XPS, survey spectra are shown in Figure S1) confirmed the presence of the two metals after surface modification, as revealed by the appearance of two $\mathrm{Ni} 2 \mathrm{p}_{3 / 2}$ peaks at 851.9 and $855.8 \mathrm{eV}$ (Figure 2e), corresponding respectively to $\mathrm{Ni}^{0}$ and oxidized $\mathrm{Ni}$ (generated during thermal annealing before $\mathrm{NiFe}$ deposition), as well as the $\mathrm{Fe} 2 \mathrm{p}_{3 / 2}$ peak (Figure $2 \mathrm{f}$ ) at $710.8 \mathrm{eV}$. The analysis of these two regions allowed to estimate a $\mathrm{Ni} / \mathrm{Fe}$ ratio of $13 \pm 5$, a stoichiometry that fits well with those reported for highly-efficient OER-active $\mathrm{Ni}_{1-\mathrm{x}} \mathrm{Fe}_{\mathrm{x}} \mathrm{OOH}$ materials. This oxyhydroxide species is the known OER-active phase for NiFe mixed oxides, that is electrochemically generated at the OER potential. ${ }^{28}$ The successful electrodeposition of NiFe on the surface was further confirmed by X-ray absorption near edge structure (XANES, Figure 2g), which showed no signal at the Fe K-edge after the first electrodeposition step but clearly exhibited an edge at E0 $=7133 \mathrm{eV}$ after the second electrodeposition step. These results confirm that our preparation method is effective to modify BSi surface by Ni/NiFe NPs. Next, we study the optical and photoelectrochemical properties of these surfaces. 
The total reflectance of several samples was measured using an integrating sphere in order to quantify their light-trapping ability (Figure 3a). The comparison between the reflectance spectrum obtained for planar Si (purple curve) and that measured for BSi (green curve) shows a considerable reflectance decrease caused by the multiple internal reflections of the incident light within the porous structure. In addition, it is interesting to note that the modification with the $\mathrm{Ni} / \mathrm{NiFe}$ NPs (red curve) did not affect significantly the reflectance of the BSi, that remained below $10 \%$ in the visible range. The surface was tested for OER in $1 \mathrm{M} \mathrm{NaOH}$ (measured $\mathrm{pH}=$ 13.6), as shown by the cyclic voltammograms (CVs) of Figure 3b. In the dark, no photoresponse could be obtained (black curve). In contrast, high photocurrents were recorded under illumination with simulated sunlight (AM 1.5G, $100 \mathrm{~mW} \mathrm{~cm}^{-2}$, red curve). TEM experiments, performed on a photoanode that was employed for OER during $50 \mathrm{CV}$ cycles, demonstrated the good adhesion of the NPs on the BSi surface (Figure 1d). The photoelectrochemical measurements obtained for 10 independently-prepared electrodes (Table S1), allowed to calculate benchmark values of maximum photocurrent $j_{\max }=23.8 \pm 0.8 \mathrm{~mA} \mathrm{~cm}^{-2}$ and photocurrent density at the standard potential of the $\mathrm{O}_{2} / \mathrm{H}_{2} \mathrm{O}$ couple, $j_{1.23 \mathrm{~V}}=4.3 \pm 0.8 \mathrm{~mA} \mathrm{~cm}{ }^{-2}$. In contrast, non-modified BSi surfaces failed to promote OER, as shown by the CV obtained under illumination with such a surface (green curve in Figure 3b). Photocurrent spectroscopy, recorded with a modified BSi surface at $+2 \mathrm{~V}$, revealed that the incident photon-to-current efficiency (IPCE, red curve in Figure 3b) is comprised between 50 and $68 \%$ in the visible range. The integrated value of the photocurrent spectrum (purple curve in Figure 3b) obtained by using the IPCE and the AM 1.5G solar spectrum is in good agreement $\left(22.8 \mathrm{~mA} \mathrm{~cm}^{-2}\right)$ with the value obtained by cyclic voltammetry at the same potential, confirming the validity of our measurements. An optical detection system was employed to measure the quantity of produced 
$\mathrm{O}_{2}$ during a 30 min-long preparative electrolysis (red curve in Figure 3d). This measurement, which was performed under illumination, confirmed that $\mathrm{O}_{2}$ was produced when the modified photoanode was biased at $+2 \mathrm{~V}(t=15 \mathrm{~min})$, which ceased immediately when the polarization was stopped ( $t=45 \mathrm{~min}$ ). The calculated production rate is $220.6 \mu \mathrm{mol} \mathrm{h}^{-1} \mathrm{~cm}^{-2}$. Based on the electrical charge consumed during this experiment (the chronoamperogram (CA) is shown in Figure S2), we calculated the theoretical amount of $\mathrm{O}_{2}$, that is plotted as purple disks in Figure 3d. Taking into account the experimental and the theoretical numbers of mole of $\mathrm{O}_{2}$, we calculated a Faradaic efficiency $(\eta)$ of $96 \%$. The stability of a photoanode was tested by a prolonged electrolysis test at $+2 \mathrm{~V}$ in $1 \mathrm{M} \mathrm{NaOH}$ (Figure 3e), which revealed that OER could be performed over $16 \mathrm{~h}$ with a rather slow degradation of the electrode, as shown by the fact that it maintained a photocurrent higher than $75 \%$ of its initial value at the end of the test.

The performance of our photoanodes is compared with that of other reported systems based on structured $n$-type Si in Table S2. Note that in this table, we have deliberately omitted the electrodes based on a Si homojunction (e.g. $\left.n p^{+}-\mathrm{Si}\right)$, that require additional fabrication steps and fall outside the scope of the present article. From that table, it can be observed that our method is the only one that does not imply the use of a conformal protection layer (such as $\mathrm{ALD} \mathrm{TiO}_{2}$ ) and that is entirely based on wet methods. Interestingly, we can also notice that our operation time is the highest that has been reported so far for protection-free structured photoanodes and that the performance we obtained in terms of $j_{1.23 \mathrm{~V}}$ and operation time is higher than that reported for BSi using an ALD-deposited $\mathrm{TiO}_{2}$ protection layer. ${ }^{22}$

In conclusion, we have reported a new strategy based on simple, low-cost wet methods to manufacture BSi-based photoanodes. The light-trapping $n$-type BSi substrate is prepared by a 
fast ( $<10 \mathrm{~min}$ ) double-step technique, and then covered by Ni/NiFe NPs using aqueous electrodeposition. In this system, the Ni cores generate an effective pinched-off heterogeneous junction with $n-\mathrm{Si}^{24}$ and the NiFe layer promote efficient OER catalysis. These photoanodes can operate for $16 \mathrm{~h}$, producing $\mathrm{O}_{2}$ at high rates with a quasi-quantitative Faradaic efficiency. To date, this is the first example reported of buried homojunction-free and protection layer-free BSi only based on simple wet methods. In addition, these results demonstrate that the stabilization of $n$-Si by electroplated Ni NPs, which was reported for planar $\mathrm{Si}(100),{ }^{13,14}$ is also effective on structured $n$-Si. We are confident that these results will inspire other groups to develop original designs for photoanodes that will be employed for cost-effective water splitting PECs. 


\section{FIGURES}
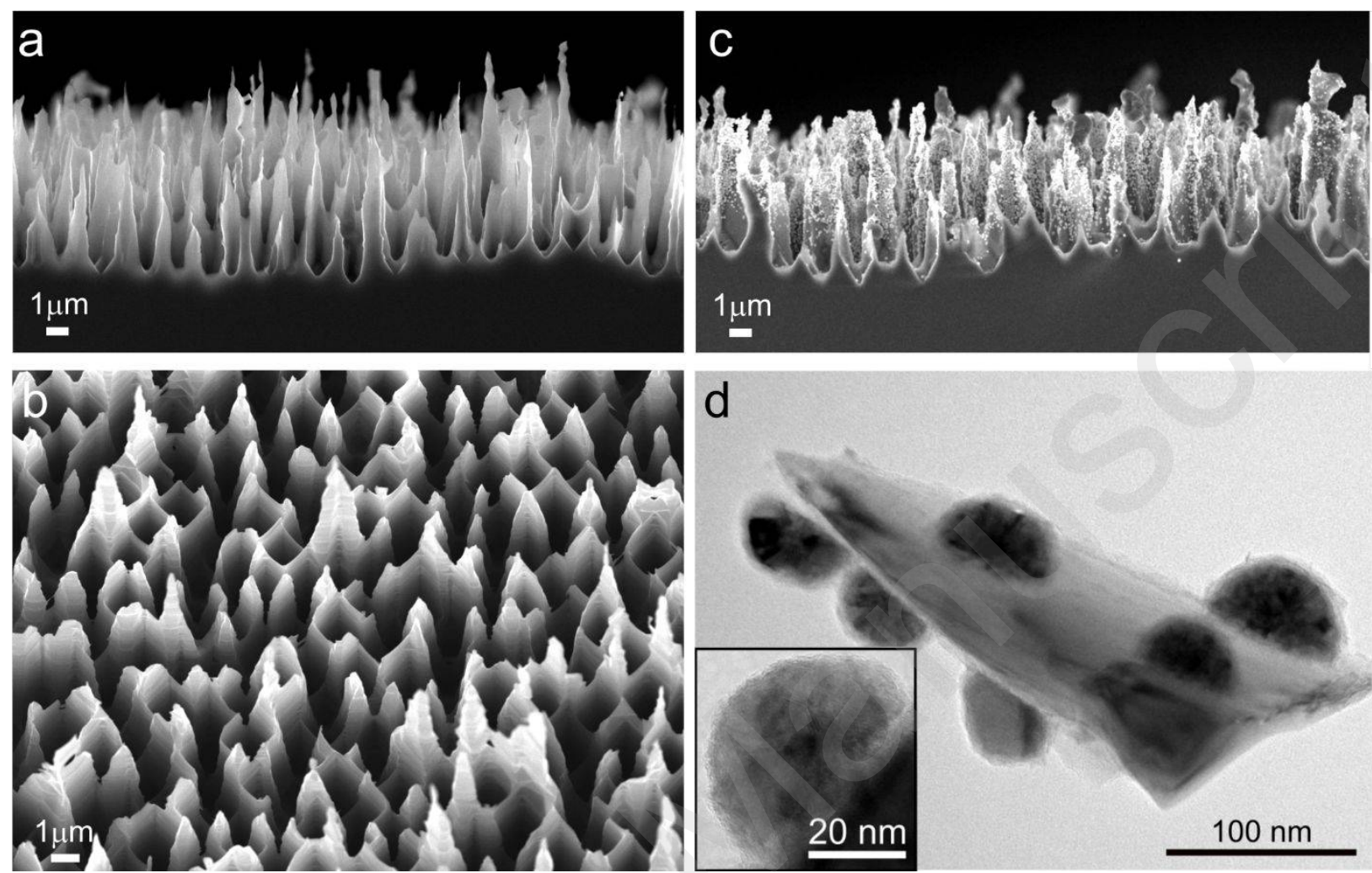

$100 \mathrm{~nm}$

Figure 1. Structural characterization of the BSi photoanodes. a) Cross-section SEM picture showing the BSi layer before electrodeposition. b) Tilted SEM picture showing the top of the BSi surface. c) Cross-section SEM picture showing the BSi layer after electrodeposition of the $\mathrm{Ni} / \mathrm{NiFe}$ NPs. d) TEM picture showing a modified BSi spike detached from the layer (in this case the surface has been employed for OER, vide infra). Inset: high magnification TEM picture showing a single $\mathrm{Ni} / \mathrm{NiFe} \mathrm{NP}$ after electrodeposition of $\mathrm{NiFe}$. 

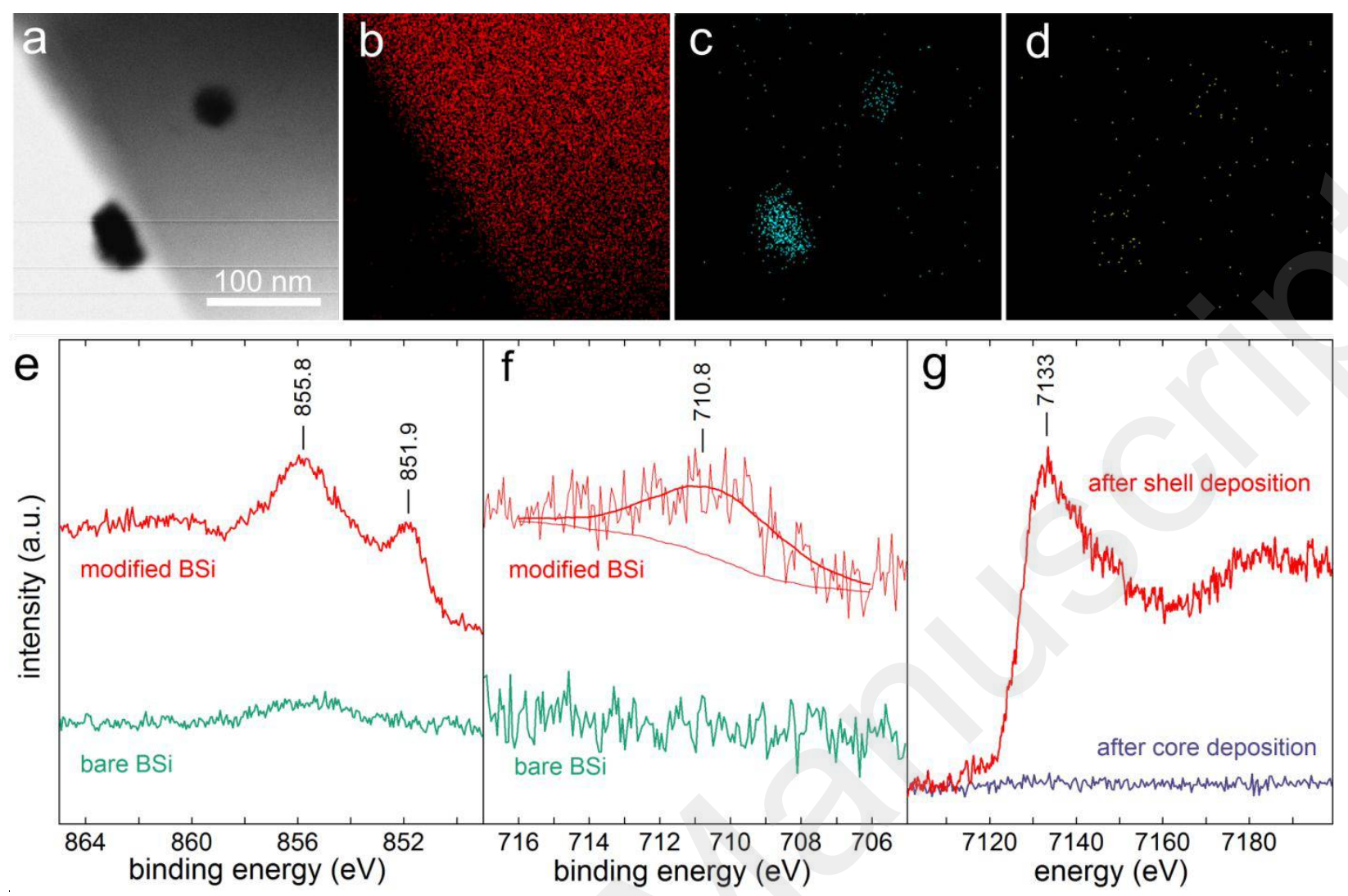

Figure 2. Chemical characterization of the BSi photoanodes. a) Bright field STEM picture image of Ni/NiFe NPs deposited on BSi and corresponding b) Si, c) Ni and d) Fe EDS maps. e,f) XPS spectra showing the $\mathrm{Ni} 2 \mathrm{p}_{3 / 2}$ and the Fe $2 \mathrm{p}_{3 / 2}$ regions. g) XANES spectra recorded at the Fe K-edge. In e-g), the green spectra were recorded before Ni electrodeposition, the purple spectrum was recorded after $\mathrm{Ni}$ electrodeposition and the red spectra were recorded after $\mathrm{NiFe}$ electrodeposition. 

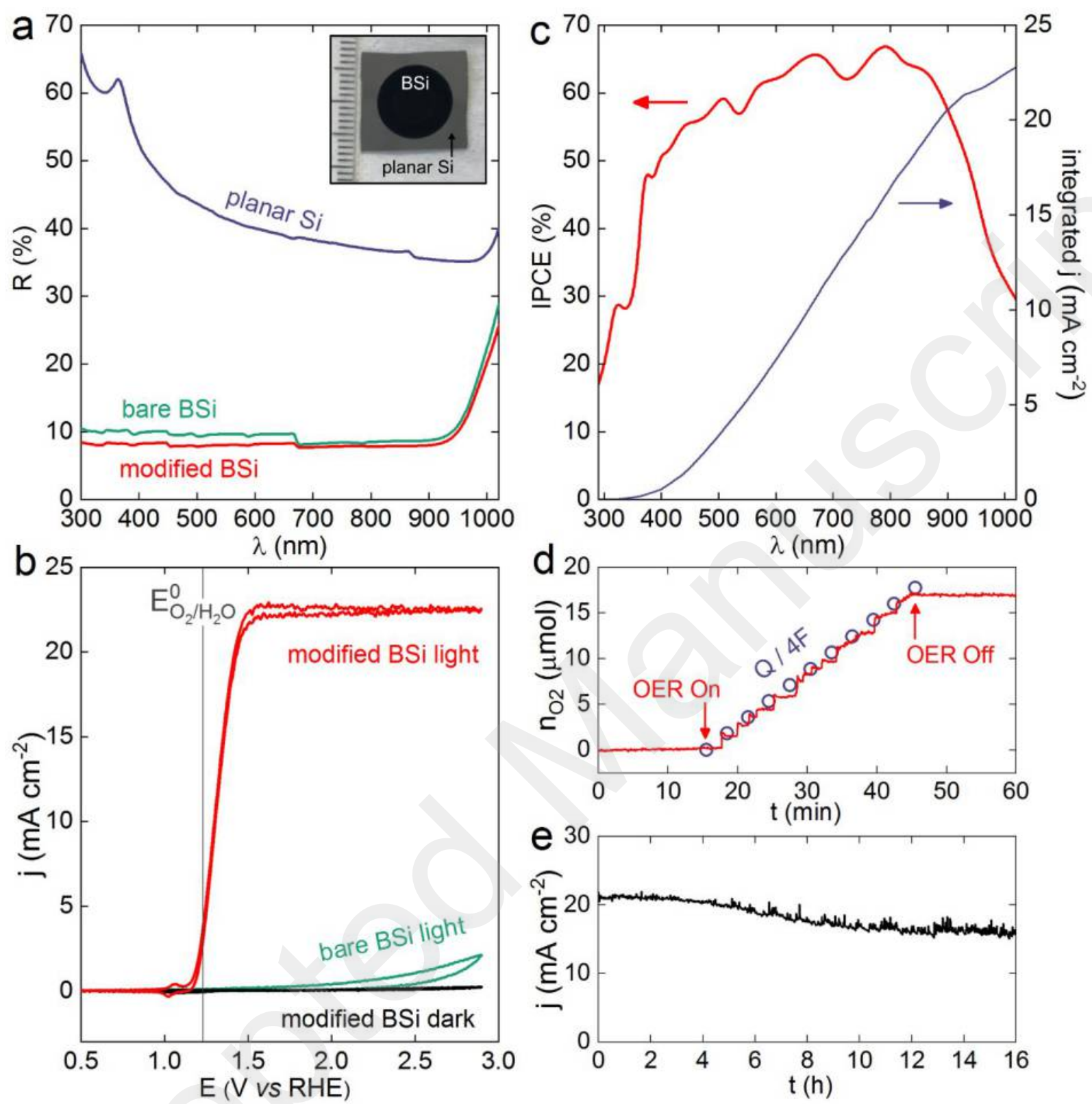

Figure 3. Optical and photoelectrochemical characterization of the BSi photoanodes. a) Total

reflectance spectra. Inset: photograph showing the visual appearance of a BSi disk prepared on a flat Si square. b) Cyclic voltammograms recorded in the dark (black curve) or under simulated sunlight (colored curves) at $100 \mathrm{mV} \mathrm{s}^{-1}$ in $1 \mathrm{M} \mathrm{NaOH}$ (not corrected from the Ohmic drop). c) IPCE spectrum (red curve) and corresponding integrated photocurrent (purple curve) recorded at $+2 \mathrm{~V} v s$ RHE. d) Experimentally measured (red curve) and theoretical (purple disks) $\mathrm{O}_{2}$ detection 
curves, obtained during an electrolysis at $+2 \mathrm{~V}$ vs RHE under illumination with simulated sunlight.

e) Chronoamperogram showing the photocurrent density as a function of time during a preparative electrolysis at $+2 \mathrm{~V}$ vs RHE under illumination with simulated sunlight. In a,b) the purple curve was recorded on planar $\mathrm{Si}$, the green curves were recorded on bare BSi and the red curves were recorded on $\mathrm{Ni} / \mathrm{NiFe}$-modified $\mathrm{BSi}$. 


\section{SCHEME}

Scheme 1. Scheme showing the fabrication steps that were employed to prepare the BSi photoanodes.

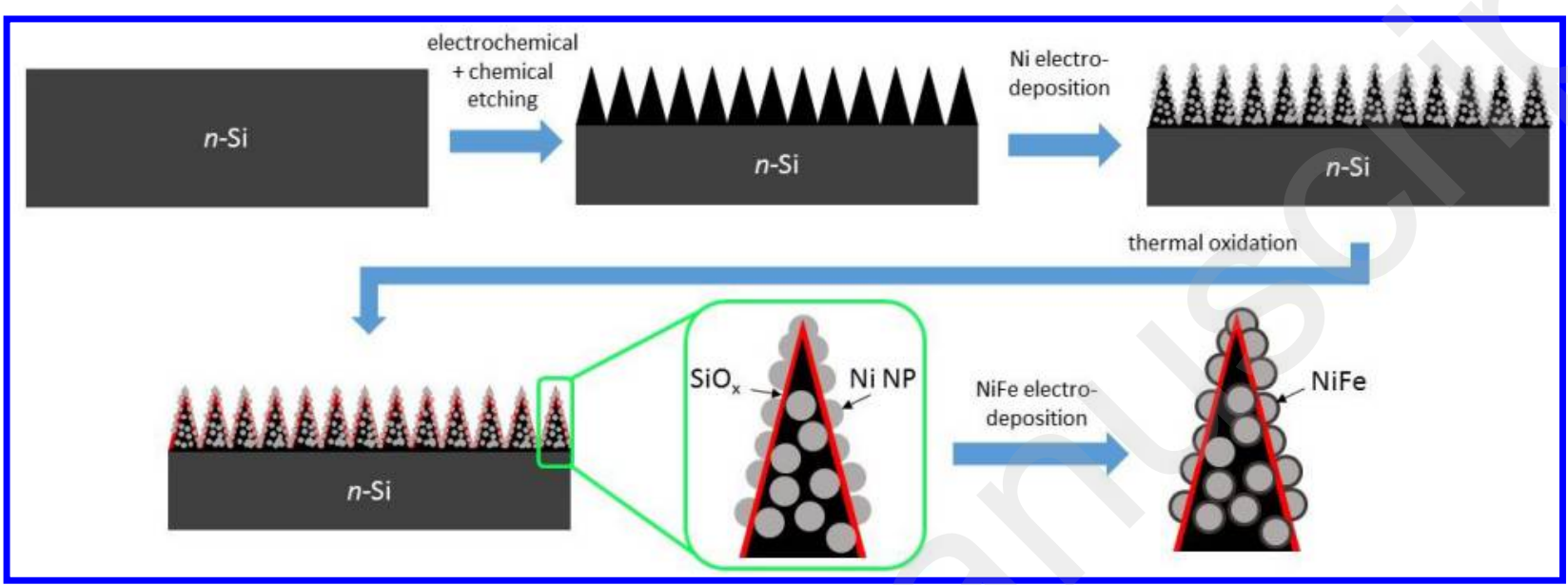




\title{
ASSOCIATED CONTENT
}

Supporting Information. Experimental section, XPS survey spectra, supplementary figures, and tables are provided in supporting information. The following files are available free of charge.

\section{AUTHOR INFORMATION \\ Corresponding Author \\ *gabriel.loget@univ-rennes1.fr}

\begin{abstract}
Author Contributions
The manuscript was written through contributions of all authors. All authors have given approval to the final version of the manuscript.
\end{abstract}

\section{Funding Sources}

This work is funded by Agence Nationale de la Recherche, ANR (project EASi-NANO, ANR16-CE09-0001-01). 


\section{REFERENCES}

(1) Lewis, N. S.; Nocera, D. G. Powering the Planet: Chemical Challenges in Solar Energy Utilization. Proc. Natl.Acad.Sci. 2006, 103, 15729-15735.

(2) Abbott, D. Keeping the Energy Debate Clean: How Do We Supply the World's Energy Needs? Proc. IEEE 2010, 98, 42-66.

(3) Fujishima, A.; Honda, K. Electrochemical Photolysis of Water at a Semiconductor Electrode. Nature 1972, 238, 37-38.

(4) Gerischer, H. Solar Photoelectrolysis with Semiconductor Electrodes. In Solar Energy Conversion: Solid-State Physics Aspects; Seraphin, B. O., Ed.; Springer: Berlin, Heidelberg, 1979; pp 115-172.

(5) Zhu, J.; Yu, Z.; Fan, S.; Cui, Y. Nanostructured Photon Management for High Performance Solar Cells. Mater. Sci.Eng. R Reports 2010, 70, 330-340.

(6) Sun, K.; Shen, S.; Liang, Y.; Burrows, P. E.; Mao, S. S.; Wang, D. Enabling Silicon for Solar-Fuel Production. Chem. Rev. 2014, 114, 8662-8719.

(7) Bae, D.; Seger, B.; Vesborg, P. C. K.; Hansen, O.; Chorkendorff, I. Strategies for Stable Water Splitting via Protected Photoelectrodes. Chem. Soc. Rev. 2017, 46, 1933-1954.

(8) Zhang, X. G. Electrochemistry of Silicon and Its Oxide; Kluwer Academic, 2001.

(9) Scheuermann, A. G.; Lawrence, J. P.; Kemp, K. W.; Ito, T.; Walsh, A.; Chidsey, C. E. D.; Hurley, P. K.; McIntyre, P. C. Design Principles for Maximizing Photovoltage in MetalOxide-Protected Water-Splitting Photoanodes. Nat.Mater. 2016, 15, 99.

(10) Hu, S.; Shaner, M. R.; Beardslee, J. A.; Lichterman, M.; Brunschwig, B. S.; Lewis, N. S. Amorphous $\mathrm{TiO}_{2}$ Coatings Stabilize Si, GaAs, and GaP Photoanodes for Efficient Water Oxidation. Science. 2014, 344, 1005-1009.

(11) Digdaya, I. A.; Adhyaksa, G. W. P.; Trześniewski, B. J.; Garnett, E. C.; Smith, W. A. Interfacial Engineering of Metal-Insulator-Semiconductor Junctions for Efficient and Stable 
Photoelectrochemical Water Oxidation. Nat. Commun. 2017, 8, 15968.

(12) Ji, L.; Hsu, H. Y.; Li, X.; Huang, K.; Zhang, Y.; Lee, J. C.; Bard, A. J.; Yu, E. T. Localized Dielectric Breakdown and Antireflection Coating in Metal-Oxide-Semiconductor Photoelectrodes. Nat. Mater. 2017, 16, 127-131.

(13) Loget, G.; Fabre, B.; Fryars, S.; Mériadec, C.; Ababou-Girard, S. Dispersed Ni Nanoparticles Stabilize Silicon Photoanodes for Efficient and Inexpensive SunlightAssisted Water Oxidation. ACS Energy Lett. 2017, 2, 569-573.

(14) Oh, K.; Mériadec, C.; Lassalle-Kaiser, B.; Dorcet, V.; Fabre, B.; Ababou-Girard, S.; Joanny, L.; Gouttefangeas, F.; Loget, G. Elucidating the Performance and Unexpected Stability of Partially Coated Water-Splitting Silicon Photoanodes. Energy Environ. Sci. 2018, 11, 2590-2599.

(15) Hill, J. C.; Landers, A. T.; Switzer, J. A. An Electrodeposited Inhomogeneous Metalinsulator-semiconductor Junction for Efficient Photoelectrochemical Water Oxidation. Nat. Mater. 2015, 14, 1150-1155.

(16) Xu, G.; Xu, Z.; Shi, Z.; Pei, L.; Yan, S.; Gu, Z.; Zou, Z. Silicon Photoanodes Partially Covered by Ni@Ni(OH $)_{2}$ Core-shell Particles for Photoelectrochemical Water Oxidation. ChemSusChem 2017, 10, $2897-2903$.

(17) Lee, S. A.; Lee, T. H.; Kim, C.; Lee, M. G.; Choi, M.-J.; Park, H.; Choi, S.; Oh, J.; Jang, H. W. Tailored $\mathrm{NiO}_{\mathrm{x}} / \mathrm{Ni}$ Cocatalysts on Silicon for Highly Efficient Water Splitting Photoanodes via Pulsed Electrodeposition. ACS Catal. 2018, 7261-7269.

(18) Kasemthaveechok, S.; Oh, K.; Fabre, B.; Bergamini, J.-F.; Mériadec, C.; Ababou-Girard, S.; Loget, G. A General Concept for Solar Water-Splitting Monolithic Photoelectrochemical Cells Based on Earth-Abundant Materials and a Low-Cost Photovoltaic Panel. Adv. Sustain. Syst. 2018, 2, 1800075.

(19) Tung, C. W.; Chuang, Y.; Chen, H. C.; Chan, T. S.; Li, J. Y.; Chen, H. M. Tunable Electrodeposition of Ni Electrocatalysts onto Si Microwires Array for Photoelectrochemical Water Oxidation. Part. Part. Syst. Charact. 2018, 35, 1700321. 
(20) Liu, X.; Coxon, P. R.; Peters, M.; Hoex, B.; Cole, J. M.; Fray, D. J. Black Silicon: Fabrication Methods, Properties and Solar Energy Applications. Energy Environ. Sci. 2014, 7, 3223-3263.

(21) Oh, J.; Deutsch, T. G.; Yuan, H.-C.; Branz, H. M. Nanoporous Black Silicon Photocathode for $\mathrm{H}_{2}$ Production by Photoelectrochemical Water Splitting. Energy Environ. Sci. 2011, 4, 1690-1694.

(22) Yu, Y.; Zhang, Z.; Yin, X.; Kvit, A.; Liao, Q.; Kang, Z.; Yan, X.; Zhang, Y.; Wang, X. Enhanced Photoelectrochemical Efficiency and Stability Using a Conformal $\mathrm{TiO}_{2}$ Film on a Black Silicon Photoanode. Nat. Energy 2017, 2, 17045.

(23) Loget, G.; Vacher, A.; Fabre, B.; Gouttefangeas, F.; Joanny, L.; Dorcet, V. Enhancing Light Trapping of Macroporous Silicon by Alkaline Etching: Application for the Fabrication of Black Si Nanospike Arrays. Mater. Chem. Front. 2017, 1, 1881-1887.

(24) Loget, G. Water Oxidation with Inhomogeneous Metal-Silicon Interfaces. Curr. Opin. Colloid Interface Sci. 2019. in press, DOI: 10.1016/j.cocis.2019.01.001.

(25) Laskowski, F. A. L.; Nellist, M. R.; Venkatkarthick, R.; Boettcher, S. W. Junction Behavior of N-Si Photoanodes Protected by Thin Ni Elucidated from Dual Working Electrode Photoelectrochemistry. Energy Environ. Sci. 2017, 10, 570-579.

(26) Tung, R. T. The Physics and Chemistry of the Schottky Barrier Height. App. Phys. Rev. 2014, $1,011304$.

(27) McCrory, C. C. L.; Jung, S.; Ferrer, I. M.; Chatman, S. M.; Peters, J. C.; Jaramillo, T. F. Benchmarking Hydrogen Evolving Reaction and Oxygen Evolving Reaction Electrocatalysts for Solar Water Splitting Devices. J. Am. Chem. Soc. 2015, 137, 43474357.

(28) Stevens, M. B.; Enman, L. J.; Batchellor, A. S.; Cosby, M. R.; Vise, A. E.; Trang, C. D. M.; Boettcher, S. W. Measurement Techniques for the Study of Thin Film Heterogeneous Water Oxidation Electrocatalysts. Chem. Mater. 2017, 29, 120-140. 


\section{SYNOPSIS}

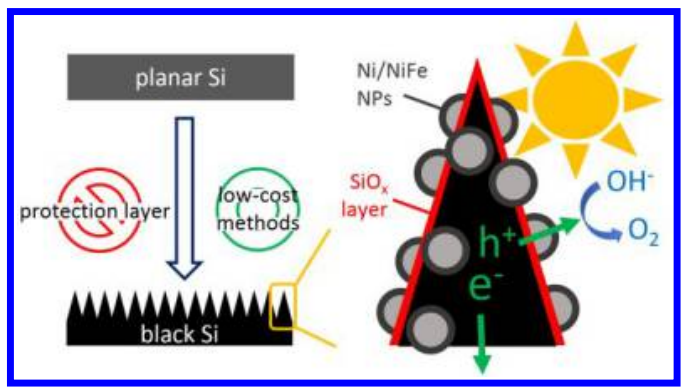

ACS Paragon Plus Environment 